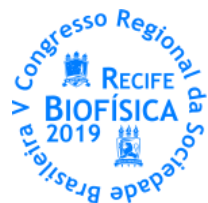

\title{
ALTERAÇÕES ELETROFISIOLÓGICAS DO SEGMENTO ABDOMINAL DO NERVO VAGO DE RATOS INDUZIDOS AO DIABETES POR STZ NO PERÍODO ADULTO
}

\author{
Lívia Carolina Amâncio ${ }^{1 *}$, Rutyleia Alves-Soares ${ }^{2}$, Amauri Barbosa da Silva-Junior², Antonio Lucas Fernandes-Leal ${ }^{2}$, \\ Maria Natália Feitosa de Sousa ${ }^{2}$,Kerly Shamyra Silva-Alves ${ }^{1}$, José Henrique Leal-Cardoso ${ }^{1}$, Andrelina Noronha \\ Coelho-de-Souza ${ }^{2}$, Walber Ferreira-da-Silva ${ }^{1,3}$, Alan Hílame Diniz Gomes ${ }^{2}$, Larissa Batista Bessa ${ }^{2}$
}

${ }^{1}$ Laboratório de Eletrofisiologia; ${ }^{2}$ Laboratório de Fisiologia Experimental. Instituto Superior de Ciências Biomédicas- Universidade Estadual do Ceará; ${ }^{3}$ Universidade Estadual Vale do Acaraú. *carol.amancio143@gmail.com

\section{INTRODUÇÃO}

O Diabetes mellitus (DM) é uma doença metabólica caracterizada por uma hiperglicemia resultante de defeitos na secreção de insulina, na ação da insulina ou em ambos. Essa doença pode provocar alterações na atividade elétrica dos nervos e acometer tanto fibras mielinizadas como não-mielinizadas. 0 nervo vago (NV) é o principal nervo do Sistema Nervoso Autonômico, e alterações em sua função podem comprometer vários sistemas, dentre eles o sistema digestório. Assim, objetivou-se avaliar as propriedades eletrofisiológicas do segmento abdominal do NV de animais diabéticos, após 12 semanas da indução por estreptozotocina (STZ).

\section{MATERIAIS E MÉTODOS}

Foram utilizados ratos Wistar (Rattus novergicus) machos, com massa entre 180 a $200 \mathrm{~g}$. Os animais foram fornecidos pelo Biotério da Universidade Estadual do Ceará (UECE) e o estudo ocorreu após aprovação do Comitê de Ética para Uso de Animais (CEUA-UECE) sob código 01163609/2019. Para esse estudo, os grupos foram divididos em: controle não diabético (CLT, $n=8)$ e diabético (DM, $\mathrm{n}=9$ ). Para indução do diabetes foi administrado STZ em dose única de $65 \mathrm{mg} / \mathrm{kg}$ (i.p.) na $8^{\mathrm{a}}$ semana de vida dos animais e estes foram acompanhados por 3 meses após a indução. Após a indução, foram aferidos os seguintes parâmetros: glicemia de jejum, peso, ingesta de água e ração e diurese. Ao término do acompanhamento foi realizado a eutanásia e em seguida foi dissecado o NV da porção do tronco cervical até o estômago. Após dissecção, o NV foi colocado em uma câmara de Harvard com solução nutridora de Locke, cuja posição para estímulo foi a parte proximal do estômago. Para estudo da atividade elétrica do NV, foi registrado o potencial de ação composto (PAC) das fibras não-mielinizadas utilizando protocolos de estímulos adequados (pulsos de $60 \mathrm{~V}$ e $1,5 \mathrm{~ms}$ de duração, a frequência de $0,2 \mathrm{~Hz}$ ). 0 s resultados obtidos foram avaliados por análise de variância com um ou dois critérios (ANOVA - One way ou Two way, com nível de significância de $P \leq 0,05$ ) seguido do pós-teste Holm-Sidak e expressos em média \pm EPM.

\section{RESULTADOS E DISCUSSÃO}

No registro do PAC, observou-se a presença de uma onda, denominada $1^{\circ}$ componente, cuja velocidade de condução no CTL foi $1,566 \pm 0,284 \mathrm{~m} / \mathrm{s}$ e para o $D M$, a velocidade foi $1,792 \pm 0,497 \mathrm{~m} / \mathrm{s}$. Com relação a excitabilidade, a reobase e cronaxia do CLT foram $15,25 \pm 1,25 \mathrm{~V}$ e $681,3 \pm 62,63 \mu \mathrm{s}$, respectivamente. No $\mathrm{DM}$ esses valores foram $16,00 \pm 0,58 \mathrm{~V}$ e $661,1 \pm 66,55 \mu \mathrm{s}$. A duração dos grupos CLT e DM para o $1^{\circ}$ componente foi $8,36 \pm 3,31$ e $15,80 \pm 5,51 \mathrm{~ms}$, respectivamente. A amplitude da $1^{\circ}$ componente dos grupos CLT e DM foram $0,114 \pm 0,04$ e $0,37 \pm 0,12 \mathrm{~A}(\mathrm{p}<0,05)$, respectivamente. Ao avaliar as propriedades de condutibilidade do PAC (Figura 2), observou-se a aumento significativo da amplitude da $1^{\text {a }}$ componente no grupo CLT $(0,114 \pm 0,04 \mathrm{~A})$ em relação ao $\mathrm{DM}(0,37 \pm 0,12 \mathrm{~A})$. Não houveram alterações significativas da Duração e Velocidade ou Reobase e Cronaxia.
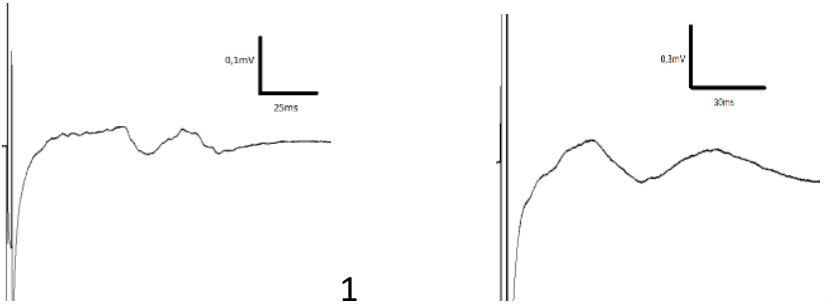

Figura 1. Traçado Representativo do PAC. Painel 1 representada o traçado do Grupo CTL. Painel 2 representa o traçado do grupo DM. (Fonte: Dados da Pesquisa).
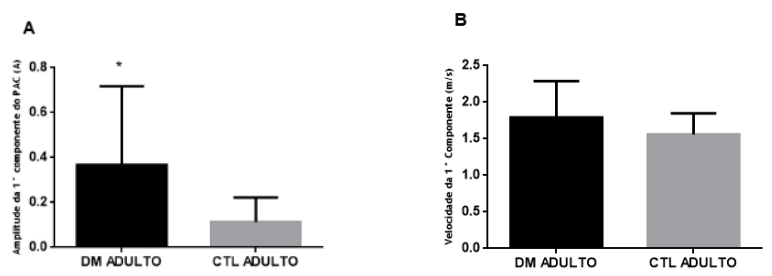

c
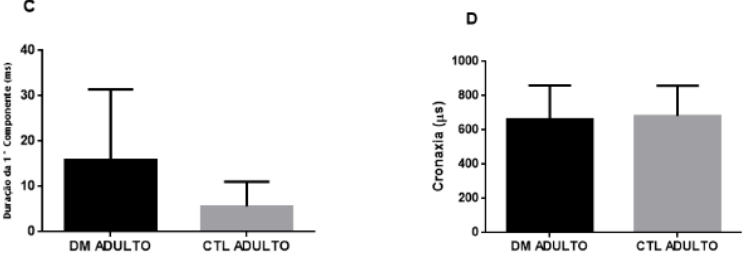

E

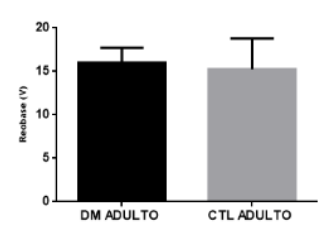

Figura 2. Alterações eletrofisiológicas no DM induzido por STZ. Dados representados por média \pm EPM (ANOVA one way, seguido por pós-teste de HolmSidak, $\mathrm{p}<0,05$ ) (Fonte: Dados da Pesquisa). 


\section{CONCLUSÕES}

Os dados preliminares sugerem que o DM pode acarretar em alterações eletrofisiológicas no NV; em consequência podendo afetar o trato gastrintestinal.

\section{REFERÊNCIAS}

SILVA-ALVES, Kerly Shamyra. Estudo das alterações produzidas pelo diabetes mellitus sobre os neurônios do nervo vago e do gânglio nodoso. Tese (Doutorado em Biotecnologia). Rede Nordeste de Biotecnologia, Fortaleza, 2014. 